\section{Commentary: Handmade back-table aortic stent-graft modifications - a must-have skill for every aortic surgeon}

\author{
Roland Assi, MD, MMS, and Arnar Geirsson, MD
}

Battocchio and colleagues ${ }^{1}$ describe a back-table custom fenestration of a thoracic endovascular aortic repair (TEVAR) stent-graft for the treatment of blunt thoracic aortic injury in a patient with a left vertebral artery originating from the distal aortic arch. They include a very elegant step-by-step description of the fenestration and how to size it and reinforce it. The fenestration was designed to perfuse both the left subclavian and left vertebral arteries. After deployment in proximal landing zone 2 aortic arch, there was persistent endoleak from the incomplete apposition of the stent-graft to the aortic wall at the level of the fenestration. This was resolved with the deployment of a bare-metal stent inside the stent-graft, providing enough radial force to ensure proper apposition of the stent-graft to the aorta.

With the expansion of the indications of TEVAR and the availability of a wide range of devices, more patients are being treated endovascularly. Custom-tailored stent-grafts can and are being designed to accommodate particular aortic anatomy. The process can take up to many weeks, leaving patients presenting with acute pathologies with limited endovascular options. Back-table modification of off-the-shelf TEVAR stent-grafts is an appealing solution for those patients with unusual anatomy requiring urgent or emergent repair. The feasibility of back-table modifications has been demonstrated since the early times of the endovascular aortic era, when many stent-grafts required

From the Division of Cardiac Surgery, Department of Surgery, Yale University School of Medicine, New Haven, Conn.

Disclosures: Dr Geirsson is a member of Medtronic's Strategic Surgical Advisory Board. Dr Assi reported no conflicts of interest.

The Journal policy requires editors and reviewers to disclose conflicts of interest and to decline handling or reviewing manuscripts for which they may have a conflict of interest. The editors and reviewers of this article have no conflicts of interest.

Received for publication March 7, 2020; revisions received March 7, 2020; accepted for publication March 11, 2020; available ahead of print April 4, 2020.

Address for reprints: Arnar Geirsson, MD, 330 Cedar St, New Haven, CT 06519 (E-mail: arnar.geirsson@yale.edu).

JTCVS Techniques 2020;3:46

2666-2507

Published by Elsevier Inc. on behalf of The American Association for Thoracic Surgery. This is an open access article under the CC BY-NC-ND license (http:// creativecommons.org/licenses/by-nc-nd/4.0/).

https://doi.org/10.1016/j.xjtc.2020.03.027

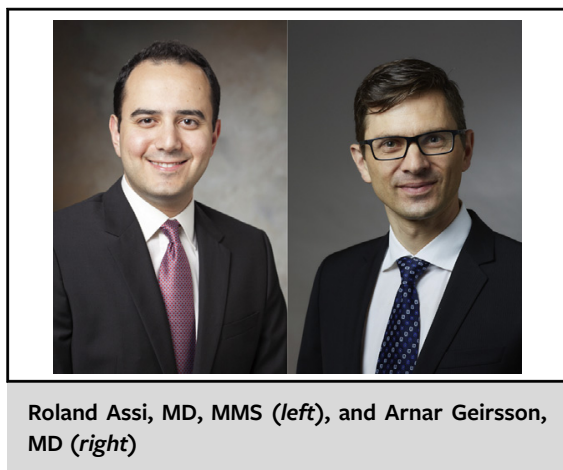

CENTRAL MESSAGE

Back-table modifications of aortic stent-grafts for emergent

repair are feasible but require perfect technical execution and knowledge of the device's characteristics as well as its limitations.

some degree of alteration on the back table to accommodate for the anatomy or the pathology.

In the case by Battocchio and colleagues, there were many technical considerations. First, there were no options for debranching or bypass in the neck due to the associated traumatic injuries. Second, the size of the fenestration was relatively large to accommodate for both the left subclavian and the left vertebral arteries. Third, the location of a freestanding fenestration with no side-branch support in an extremely curved part of the aorta (transition between zone 2, 3, and descending thoracic aorta) decreases the chances of a perfect seal. Despite these challenges, accurate sizing and deployment achieved excellent positioning of the stent-graft. The use of a bare-metal stent improved the seal to the aortic wall and resolved the endoleak.

To achieve consistent success with handmade modified stent-grafts, we believe that aortic surgeons should be familiar with the characteristics of the devices they have on the shelf and acquire an understanding of what modifications can be made without affecting the device's performance. Patients should receive follow-up imaging for rest of their life until we learn about the durability of handmade modifications.

\section{Reference}

1. Battocchio P, Piazza M, Squizzato F, Antonello M. Modified stent-graft for emergent repair of blunt thoracic aortic injury. J Thorac Cardiovasc Surg Tech. 2020;3:43-5. 